\title{
The Influence of Human Resource Practices and Collective Affective Organizational Commitment on Aggregate Voluntary Turnover
}

Timothy M. Gardner

Lisa M. Moynihan

Patrick M. Wright

Working Paper 07 - 12 


\title{
The Influence of Human Resource Practices and Collective Affective Organizational Commitment on Aggregate Voluntary Turnover
}

\author{
by \\ Timothy M. Gardner \\ Owen Graduate School of Management \\ Vanderbilt University \\ $40121^{\text {st }}$ Ave. South \\ Nashville, TN 37203 \\ tim.gardner@vanderbilt.edu \\ Lisa M. Moynihan \\ London Business School \\ Regent's Park \\ London NW1 4SA \\ United Kingdom \\ Imoynihan@london.edu \\ Patrick M. Wright \\ Cornell University \\ Center for Advanced Human Resource Studies \\ 397 Ives East \\ Ithaca, NY 14853-3901 \\ pmw6@cornell.edu
}

August 2007

\section{http://www.ilr.cornell.edu/cahrs}

This paper has not undergone formal review or approval of the faculty of the ILR School. It is intended to make results of Center research available to others interested in preliminary form to encourage discussion and suggestions.

Most (if not all) of the CAHRS Working Papers are available for reading at the Catherwood Library. For information on what's available link to the Cornell Library Catalog: http://catalog.library.cornell.edu if you wish. 


\section{Abstract}

This research was supported by a grant from the Center for Advanced Human Resource Studies at Cornell University, Ithaca, NY. Thanks to the participants and discussants of the 2007 Human Capital Conference hosted by the Wharton School for suggestions and improvements. 


\section{The Influence of Human Resource Practices and Collective Affective Organizational Commitment on Aggregate Voluntary Turnover}

\section{Introduction}

After thousands of published studies, voluntary turnover remains a relevant and interesting topic of study for organizational scholars. The vast majority of these studies examine the question of why individuals voluntarily quit organizations \{Maertz \& Campion 2004\}. This line of research specifically contributes to our understanding of individual turnover decisions and more broadly contributes to our understanding of the connections among organizational context, individual attitudes, skills, and behaviors. Another less studied approach treats turnover not merely as an individual behavioral phenomenon but, as a collective phenomenon understood and explained by the shared context, interactions, cognitions, and attributes of the collective members. This line of research is much more consistent with the way managers think about retaining employees in their organizations. Consider a quote from David Brandon, CEO of Domino's Pizza: “Before I joined Domino's, turnover rates were 158\%. We had 125,000 employees, so we were going through close to 200,000 people a year. We've overhauled our training program and driven turnover down more than 60\%" \{Boorstin 2005: 28\}. Clearly Mr. Brandon is not concerned with the myriad of reasons affecting each individual quit decision but has focused his resources on reducing the aggregate turnover rate of the Domino's organization; an outcome like productivity, customer satisfaction, and return on investment needing to be measured and managed \{Baysinger \& Mobley 1983\}.

Recent research has demonstrated the importance of managing aggregate voluntary turnover. A number of studies have clearly demonstrated that increased turnover is associated with declining organizational effectiveness \{Glebbeek \& Bax 2004; Shaw et al. 2005\}. Scholars and managers, however, would be committing a serious ecological fallacy by assuming the conclusions derived from studies of individual turnover apply to aggregate turnover in the same way and/or with the same intensity $\{$ Klein, et al. 1994; Rousseau 1985\}. Unfortunately, the 
literature examining the antecedents of aggregate turnover is sparse, relative to the volume of studies examining individual turnover, and is riddled with significant theoretical and methodological challenges. Thus while it is tempting to assume that the contextual and attitudinal drivers of individual turnover also drive aggregate turnover, the scarcity and shortcomings of the research stream prohibit firm conclusions. This study seeks to provide scholars with a more rigorous theoretical framework for examining the antecedents of aggregate turnover as well as an inventory and solution to many of the methodological shortcomings of past research.

The second purpose of this paper is to contribute to the strategic human resource management literature by including human resource $(H R)$ systems as a primary antecedent of aggregate turnover. As a collective phenomenon, drivers of aggregate turnover must theoretically exist and be measured at the same collective level \{Klein, et al. 1994; Rousseau 1985\}. Collective behavior is a function of, among other things, common experiences resulting from common policies and practices, such as HR management practices, used to control and direct the behavior of organizational members \{Levinson 1965; Morgeson \& Hofmann 1999 . Thus the inclusion of HR systems allows for at least two theoretical contributions. First, previous models of the antecedents of aggregate turnover have rarely included the HR systems that likely have a strong homogenizing effect on the experiences, interactions, make-up, and thus turnover of the organizational unit members. This study will shed insight into an important driver of collective turnover. Second, this study will provide insights into the mediating linkages between HR systems and organizational outcomes. Strategic HR research emerged out of the desire to verify the link between how organizations manage their people and organizational effectiveness \{Delery \& Shaw 2001\}. While there is a great deal of evidence that HR practices are at least weakly related to firm performance, the intervening variables have not been adequately tested or explored (Becker \& Gerhart 1996; Wright \& Gardner 2003). This study will 
test the role of collective commitment in both explaining collective turnover and meditating the relationship between HR systems and turnover.

\section{Theoretical Framework}

Several authors have noted that virtually all models of individual turnover are derived from March and Simon's (1958) classic book, Organizations \{Shaw, et al. 1998; Trevor 2001\}. March and Simon explained individual, voluntary turnover decisions in terms of the ease of movement to another organization and the perceived desirability of leaving the organization. Ease of movement has been operationalized both as the perceived ease of movement, meaning the individual's beliefs regarding external labor market opportunities \{Mowday, et al. 1982\} and the degree to which the skills are valued on the broader labor market \{Mobley 1982; Trevor 2001\}. Turnover models based on desirability of movement have primarily explored work attitudes such as job satisfaction and commitment as drivers of organizational exit \{Lee et al. 2004\}. For this study we will use March and Simon (1958) as a guiding framework to interpret past theoretical and empirical work and to develop a set of hypotheses describing the antecedents of aggregate turnover.

The empirical work examining the role of how an individual's attitudes affect their turnover behavior is vast and rapidly growing. The study of organizational commitment, particularly affective organizational commitment, is a major component of this research stream \{Cohen 1993; Meyer, et al. 2002\}. While the earliest conceptions of organizational commitment go back to Becker's (1960) notion of "side bets," today, organizational commitment, particularly affective commitment, is understood as a "psychological bond" an employee has with his or her employer \{Meyer \& Allen 1997: 14\}. Kanter (1968) defined commitment as “ . . the willingness of social actors to give their energy and loyalty to social systems ..." (pg. 499). Relative to the level of commitment, this psychological state of bonding, loyalty, and energy that is concentrated toward the employing organization gives direction to the behavior of the committed individual. This behavior includes pursuing courses of action that benefit the organization and 
its mission and protecting company assets. Primarily, however, the attitudinal and behavioral consequences of an affectively committed employee is continued employment in the organization \{Meyer \& Allen 1997; Meyer \& Herscovitch 2001; Mowday, et al. 1982\}. The most recent meta-analysis of the relationship between individual affective organizational commitment and actual turnover estimates the population correlation to be -0.23 \{Meyer, et al. 2002\}.

To hypothesize that collective commitment is an important antecedent to collective turnover first requires a better understanding of the construct. Drawing upon Morgeson and Hofmann (1999), we define a collective as an interdependent and goal directed combination of individuals. This could include a team, a department, a business unit, or an entire organization. This is consistent with Chan's (1998) description of a group as a collection of individuals with shared goals, embedded in an organizational context, interacting to perform interdependent tasks. Collective affective organizational commitment refers to a shared mindset or pattern of thinking and a shared psychological state among a delimited collective of individuals regarding their common employer typified by feelings of loyalty and a desire to invest mental and physical energy in helping the organization achieve its goals \{Kanter 1968; Meyer \& Allen 1997\}. Consistent with Lindsley, Brass, and Thomas (1995, pg. 648) we treat the collective of individuals as a social entity capable of thinking, feeling, and acting as a single entity. The collective mindset and feelings of bonding and loyalty are distinct from mindsets and beliefs of the individuals when they are not part of the collective.

The Link Between Affective Commitment and Turnover

March and Simon's (1958) individual-level model of the turnover process suggests that individuals compare the inducements (wages, status, peer relationships, etc.) received from their organization to their contributions to the organization. When expected or actual contributions exceed inducements, turnover is more likely. A key driver of this dynamic, they posit, is the employee's attitude toward the job and the organization; a poor attitude results in greater estimates of the costs of contributions and suppresses the estimated value of 
inducements resulting in individual exit decisions \{Hom \& Griffeth 1995; March \& Simon 1958\}. Hom and Griffeth's (1995) comprehensive review of the theoretical and empirical literature strongly supports March and Simon's (1958) work in principle.

The theoretical and empirical work exploring the linkage between collective attitudes, including commitment, and collective turnover is not nearly so refined as the work that has been done at the individual level. The first study of this kind was an elegant quasi-experiment in a single firm. Hulin (1968) looked at changes in job satisfaction and turnover before and after changes in a set of human resource practices. The theoretical framework assumed homology between the mechanisms linking individual job satisfaction with individual turnover and the aggregate job satisfaction of the employees in the workgroup and the workgroup's subsequent turnover rate. Hulin's (1968) results suggested that increases in group job satisfaction were associated with later decreases in the group's turnover rate. A number of subsequent studies examining the relationship between collective commitment and collective turnover rates have relied on a theoretical framework homologous to the theoretical mechanism linking individual commitment and turnover \{Angle \& Perry 1981; Long 1980; Simons \& Roberson 2003\}.

Ostroff's (1992) study of collective commitment and turnover intentions is the first to suggest that supra-individual factors link collective commitment and aggregate turnover rates. Instead of a direct link, Ostroff (1992) suggests that collective commitment shapes the patterns of interaction among group members. First, individuals with more defined and specific levels of commitment transmit these feelings to individuals with less defined commitment levels B Barsade 2002; Levinson 1965\}. Second, these patterns of interaction create common norms of behavioral expectations thus affecting individual and collective behavior \{Ostroff 1992; Morgeson \& Hofmann 1999\}. Thus employees working in a group with strong (positive or negative) affective commitment will, after a series of interactions with other group members, adjust their feelings and behaviors (such as turnover) to match that of their coworkers A Allen \& Grisaffe 2001\}. 
Ostroff's (1992) study demonstrated a strong negative relationship between aggregated commitment and turnover intentions. The results for Ryan et al's (1996) and Koys' (2001) studies of the relationship between aggregate job satisfaction and turnover were weak but negative. Simons and Roberson's (2003) study suggested a weak negative relationship between collective commitment and organizational turnover rates while Angle and Perry 's (1981) study of bus company employees concluded there was a strong negative relationship between affective commitment and organizational turnover. The above mentioned weak results were likely due to a failure to perform a logarithmic transformation on the ratio turnover variable (discussed in more detail below).

Based on the three theoretical mechanisms identified above, (1) the link between individual affective commitment and individual turnover will hold at the group level, (2) the transmission of attitudes and behavioral expectations among collective group members, and (3) the role that collective attitudes play in shaping group interactions, norms, and behavior, as well as the empirical evidence presented above, we expect that the level of commitment for the workgroups in this study will be associated with the workgroup's voluntary turnover rates. Hypothesis 1: The level of workgroup affective organizational commitment will be negatively associated with the workgroup's voluntary turnover rate.

\section{The Link Between HR Practices and Collective Affective Commitment}

Organizations use an almost infinite variety of combinations of human resource practices to manage the flow of employees into, through, and out of different business units, divisions, and workgroups. No two studies have used the same set of HR practices measured in the same way to describe these systems of practices \{Dyer \& Reeves 1995; Becker \& Gerhart 1996\}. A number of scholars have noted that human resource systems can be described along

three common dimensions \{Delery 1998; Dyer \& Holder 1988; Appelbaum et al. 2000\}. The first dimension is the degree of investment in HR practices intended to improve the knowledge, skills and abilities of the companies' employees. These include recruiting, training, selection, 
socialization, and any other practice functioning to enhance the workplace competencies of the employees. The second dimension is the degree of investment in HR practices functioning to motivate discretionary employee effort, creativity, and behavior. These include incentive pay plans, performance bonuses, gainsharing, and performance management systems. Finally, the third dimension is the degree of investment in HR practices functioning to provide opportunities to participate in substantive decision-making regarding work and organizational outcomes. These include such practices as quality circles, granting discretion and authority on the job, information sharing about the service or production process, and opportunities to communicate with employees and managers in other workgroups.

The scholarly literature linking human resource practices to affective organizational commitment is similar in structure to the literature linking commitment and turnover: There is a great deal of theoretical and empirical work at the individual level and almost no work at the collective level. The antecedents of individual affective organizational commitment are typically grouped into organizational factors (structure, size, etc), personal characteristics (gender, age, tenure, etc.), and work experiences (HR practices, role ambiguity, participative decision making, job challenge, etc.). Of the three, researchers have found work experiences to be the most robust antecedent of individual affective commitment \{Meyer \& Allen 1997\}.

HR practices create a set of homogeneous work experiences among employees that can lead to feelings of collective commitment. Per March and Simon (1958), ongoing exchanges of monetary and social rewards over the course of the employment relationship create the shared perception in employees that the organization cares (or does not care) about them and is reciprocated with feelings of commitment (or lack thereof) \{Eisenberger, et al. 1986; Eisenberger, et al. 2001\}. This concept of "perceived organizational support" has received extensive empirical and theoretical attention. Individual level studies suggest HR practices lead to perceived organizational support which then results in feelings of affective commitment \{Rhoades, et al. 2001; Meyer \& Smith 2000\}. Workgroups managed by common sets of HR 
practices with shared feelings of support supplemented by repeated patterns of interactions among group members will result in homogeneous feelings of commitment \{Ostroff 1992; Morgeson \& Hofmann 1999\}.

While a unitary index of HR practices can be expected to influence collective commitment, each of the three dimensions of HR practices can be expected to have unique effects. Motivation enhancing practices are expected to positively influence collective commitment. First, incentives and other rewards-for-performance practices signal a positive valuation of employee efforts thus increasing reciprocal commitment \{Meyer \& Allen 1997; Rhoades, et al. 2001\}. Second, meta-analytic research has shown that greater role ambiguity is associated with lower commitment $\{$ Mathieu \& Zajac 1990\}. Thus, incentives that direct and reward desired behaviors and outcomes will reduce such ambiguity thus increasing commitment \{Mowday, et al. 1982\}. Finally, Klein's (1987) extrinsic satisfaction model suggests that financial rewards designed to increase commitment to work outcomes align employee interests with the organizations resulting in greater commitment to the organization.

Secondly, empowerment enhancing practices are expected to have a positive impact on collective commitment. Organizations that allow employee input into decisions, share information, and treat employees with respect strengthen shared perceptions of congruence between employee and organizational values and increases employees' identification with the firm thus enhancing commitment \{Arthur 1994; Long 1980; Meyer \& Herscovitch 2001\}. Secondly, the teamwork and social interactions inherent in empowering HR practices function to accelerate the Attraction-Selection-Attrition process $\{$ Schneider 1987$\}$ thus strengthening the forces of social cohesion among group members and thus the commitment to the organization \{Morrison 2002; Osterman 1995\}.

Finally, skill enhancing practices are expected to have a positive influence on collective affective commitment. Research suggests that training investments may increase employees' perceptions that the organization values their current and future contributions and thus their 
level of commitment $\{$ Meyer \& Allen 1997; Tannenbaum, et al. 1991\}. Additionally, training may increase skill mastery, reduce role confusion, and prepare employees for future promotions thus increasing commitment \{Lincoln \& Kalleberg 1996; Pascale 1985\}. Finally, intensive hiring and selection procedures used to ensure highly competent employees may (1) make employees feel part of a special and elite group, thus increasing commitment \{Caldwell, et al. 1990\} and (2) encourage less committed employees to self select out of the hiring process \{Ryan et al. 2000\}.

Based on the theoretical arguments and empirical evidence presented above, we hypothesize the following:

Hypothesis 2a: There will be a positive relationship between the use of motivationenhancing human resource practices and collective affective commitment.

Hypothesis 2b: There will be a positive relationship between the use of empowerment enhancing human resource practices and collective affective commitment.

Hypothesis 2c: There will be a positive relationship between the use of skill enhancing human resource practices and collective affective commitment.

Since Hulin (1968), there have been a number of theoretical pieces and empirical studies that have looked at the impact of individual and sets of HR practices on collective turnover. The only consistency is the disagreement surrounding whether HR practices affect turnover directly or are mediated by attitudes. While Steers (1977) proposed partial commitment, Hom and Griffeth's (1995) exhaustive review of the individual turnover literature and Meyer et al's (2002) meta-analysis concluded that commitment fully mediates the relationship between HR practices and turnover behavior.

There are also differences of opinion in the macro literature. Although not empirically tested, Way (2002), Gould-Williams (2003), and Delery et al (1998) all hold that collective attitudes fully mediate the relationships between HR practices and organizational outcomes. On the other hand, Kopelman et al (1990) theorized partial mediation. In the only empirical examination of this question, Gelade and Ivery's (2003) results suggested that collective 
attitudes partially mediated the relationships between staffing level \& skill certification and retention and fully mediate the relationship between overtime and retention.

Our contribution to resolving this debate is to propose that the source of this theoretical and empirical confusion is organizational scholars' digression from March and Simon's (1958) turnover framework. As reviewed above, companies manage their pools and flows of human capital with three independent components of their HR system: skill enhancing, motivation enhancing, and empowerment enhancing HR practices \{Appelbaum et al. 2000; Batt 2002; Delery \& Shaw 2001\}. Matching this integrated conception of human resource management with March and Simon's (1958) framework of individual turnover behavior suggests that components of the HR system that influence employees' collective desirability of staying with the organization will influence aggregate voluntary turnover via collective affective commitment while components that influence employees' "ease of movement" to other organizations will influence turnover along with collective commitment.

As described above, motivation enhancing HR practices function to motivate discretionary effort, creativity, and behavior while empowerment enhancing HR practices function to allow opportunities for employees to participate in organizational decision making. A priori, we find no reason to hypothesize that these dimensions function to improve the market value of the skill sets of employees managed with these practices. Thus we hypothesize that the relation between motivation \{Wilson \& Peel 1991\} and empowerment enhancing\{Batt, et al. 2002; Shaw, et al. 1998\} HR practices and aggregate voluntary turnover is fully mediated by collective affective commitment.

Hypothesis 3a: The negative relationship between the use of motivation-enhancing human resource practices and aggregate voluntary turnover will be mediated by collective affective commitment.

Hypothesis $3 \mathrm{~b}$ : The negative relationship between the use of empowerment-enhancing human resource practices and aggregate voluntary turnover will be mediated by collective affective commitment. 
Unlike motivation and empowerment enhancing HR practices, we expect affective commitment to partially mediate the relationship between skill enhancing practices and aggregate voluntary turnover. Trevor (2001) defined the set of individual attributes that enhance employees' ability to secure employment outside of their employing organizations as 'movement capital.' These attributes include task specific abilities, productivity, education, cognitive abilities, and general skills. Trevor's (2001) research complements March and Simon's (1958) work on ease of movement by codifying the construct and by demonstrating that indeed employees with greater movement capital are more likely to leave their employing organization for another employer. Benson et al (2004) showed that employees using tuition reimbursement that completed post-secondary educational degrees were more likely to voluntarily leave the employing organization than those that had not completed the degrees.

The above individual-level results would suggest that HR practices that function to improve the knowledge, skills, and abilities of a group of employees will result in increased aggregate voluntary turnover (Benson, et al. 2004; Oatey 1970; Williamson, et al. 1975), yet the empirical evidence is mixed. Studies that aggregate a comprehensive set of HR practices into a single index consistently show a negative association with voluntary turnover \{Arthur 1994; Guthrie 2001; Huselid 1995; Way 2002\}. The results of studies separating skill enhancing practices from a unitary index are inconsistent. Becker's (1978) study of five occupational groups within a set of hospitals were inconclusive as continuing education programs were not associated with aggregate turnover. Shaw et al (1998) found no association between hours of formal training provided to truck drivers and the aggregate voluntary turnover of truck drivers in the surveyed firms. Batt's (2002) study of US call centers found no association between an index of skill requirements (number of years of formal education and on-the job training required for competency) and aggregate voluntary turnover. Gelade and Ivery's (2003) study of retail bank branches showed that greater professional development (percentage of branch employees certified in customer service skills) was associated with decreased voluntary turnover. 
Despite the lack-of and even contrary empirical findings, we suggest that the March and Simon (1958) framework will hold at the aggregate level. Previous studies, reviewed above, used highly construct deficient measures of the practices organizations typically use to improve the knowledge, skills, and abilities of the work force. We believe that our measures with their greater construct and content validity will demonstrate that greater use of knowledge, skill, and ability improvement practices create an aggregate skill profile that is useful and valuable to the broader labor market \{Stevens 1994a\}.

Hypothesis 3c: The positive relationship between the use of skill-enhancing human resource practices and aggregate voluntary turnover will be partially mediated by a positive association between skill enhancing practices and collective affective commitment.

\section{Methods}

\section{Setting}

A study such as this requires a sufficient number of individuals consistently employed in a large number of discrete groups (in the case of this study, workgroups) to provide moderate statistical power for testing relationships; all workgroups being in the same industry to minimize industry-specific variance; and common measures of HR practices, affective commitment, and voluntary turnover. We identified a company in the food service industry that met these requirements.

The focal company is one of the largest food service distributors in the United States. Marketing and distribution of its food and food related products are handled through its standalone business units in metropolitan areas across the country. The local management team is entirely responsible in the local marketplace for the development and execution of their strategy. With the exception of health care and retirement savings/pensions managed from the corporate headquarters, business-unit presidents are free to develop customized HRM programs. Furthermore, all business-units employ approximately 500 employees. If a unit grows too large 
to serve one market, it is divided into two separate companies to maintain an entrepreneurial spirit and customized service. Thus each operating unit is highly similar in terms of size, structure, technology, physical assets, and services provided but differ in management practices including human resource management practices.

Across the set of business units, there are six core workgroups. These include sales employees, warehouse employees, delivery drivers, front-line supervisors, merchandising employees, and administrative staff. Interviews with corporate executives confirmed that, except for administrative staff, the employees within each group work interdependently to accomplish common goals and each is managed with customized HR policies such that these policies are consistent within one job, but vary across jobs. Administrative employees is a catch-all designation for HR, IT, secretarial, and miscellaneous administrative employees that neither work together nor are managed with a common set of HR practices and thus does not meet our previous definition of a group. Thus these five discrete, non-administrative workgroups in the participating business units represent the unit of analysis in this study.

The data for the study consist of a survey of the top HR managers at each business unit describing the HR practices for the five different workgroups. At the same time data was collected from the HR executives, commitment survey data was collected from an average of 18.8 employees (range: 4 to 79 ) from 93 workgroups for a total of 1748 employees. Twelve months after the initial survey administration, the business-unit HR managers were again surveyed to assess the voluntary turnover rates for the employees in each of the five workgroups.

\section{Data Collection}

Employee surveys were developed by the authors in cooperation with corporate HR staff. HR manager surveys were developed solely by the authors. Corporate HR marketed the study to the presidents of all 62 of the corporation's business units. Participation was voluntary; 33 business unit presidents chose to participate in the employee survey during first wave of data 
collection (late 1999 and early 2000) for a business-unit participation rate of $53 \%$. Of those 33 business units, HR executives of 31 (93.9\%) agreed to complete a survey of HR practices and employee outcomes. Twelve months later, all 62 business units were again invited to participate in another round of surveys. Forty-two $(67.7 \%)$ of the business unit presidents agreed to participate in the employee survey (data not used). Of these 42 business units, HR executives from 37 business units (88.1\%) agreed to provide data about HR practices and employee outcomes, including voluntary turnover. Of the 37 business units, 20 overlapped with the 31 for which there was complete data in the first round of data collection.

There were no measurable differences between the 20 participating business units and the 42 non-participating units. There was no difference in unionization status between participating and non-participating business units. Two multivariate analyses of variance (MANOVA) comparing profitability (pre-tax profits as a proportion of sales), productivity (cartons of product sold per payroll dollar), and quality (cartons of product delivered per number of delivery errors) to compare the two groups both at time 1 (quarter before and quarter during data collection) and time 2 (quarter before and quarter during data collection) revealed no significant differences $(p<.52 ; p<.71)$.

Business-unit human resource managers were instructed by the corporate office to randomly select $20 \%$ or more of the employees from each of the workgroups for survey participation. Employees met on company time with the HR managers who explained the purpose of the meeting and the survey process. HR managers distributed the surveys to employees, gave them time to complete them, and had the employees place the surveys into one large sealable envelope per meeting. The business-unit HR managers sent the unopened envelopes directly to the researchers. The response rate for employees in these groups was $100 \%{ }^{1}$. HR managers were instructed to complete and return a survey of HR practices directly to the researchers.

\footnotetext{
${ }^{1} \mathrm{~A}$ total of 5 surveys were returned by employees entirely incomplete.
} 
The employee survey covered $10.4 \%$ of the population of business-unit employees of the entire food service division. Although business-unit HR staff were instructed to survey $20 \%$ or more of the employees from each of the workgroups, the average workgroup participation rate was $28 \%$ (sd $=18 \%$; range $0 \%$ to $100 \%$ ) This variance was due to decisions by the $\mathrm{HR}$ manager to survey fewer or more employees rather than employee participation decisions. We determined through conversations with HR managers that this variation was due to operating constraints that prevented pulling employees off their jobs. An average of 94 employee surveys were collected from each business unit. Sixty-five employees failed to identify their occupation or identified more than one occupation. Surveys with unidentifiable occupations and workgroups with no employee participation were dropped from further analysis. To ensure adequate reliability and agreement necessary for aggregation, workgroups with data from three or fewer employees were dropped from the analysis.

Measures

Affective Organizational Commitment. Field setting restrictions prevented the use of a validated measure of affective organizational commitment and instead we used questions from two different scales $\{$ Meyer \& Allen, 1997; Porter et al, 1974\}. The list of questions can be found in Table 1. The items exhibited a coefficient alpha of .85 suggesting the items hold together as a unified scale. As a step toward construct validity of our scale, we tested its relationship with another variable not included in the empirical model. Tett and Meyer's (1993) meta analysis reported a mean correlation of -.46 between organizational commitment and turnover intentions. Our measure of affective commitment exhibited a correlation of $-.47(p<.001)$ with a three item measure of turnover intentions suggesting the scale represents an acceptable measure of the construct. Thus the five questions were aggregated into a scale measure of affective organizational commitment by calculating a mean for each individual.

After a scale measure of affective commitment was constructed for each individual, we evaluated whether the scale could be aggregated to represent the collective attitudes of each 
workgroup. This involved calculating intraclass correlation coefficients (ICC). This procedure involves calculating one-way random effects ANOVAs where the variable (commitment items and scale) is the dependent variable and the workgroup membership indicator is the independent variable. $\mathrm{ICC}(1)$ represents the likelihood that a single rating from an individual provides a stable estimate of the group mean while $\operatorname{ICC}(2)$ provides an estimate of the reliability of the group mean. Table 1 lists the individual $\operatorname{ICC}(1)$ and $\operatorname{ICC}(2)$ values for each question and the entire scale. The average item ICC(1) was .15 while the $\operatorname{ICC}(1)$ for the scale was .17. Multilevel scholars generally agree that a statistically significant ANOVA is sufficient evidence that aggregation is an acceptable procedure (Klein et al, 2000). Our ANOVAs were significant at the .01 level. The average $\operatorname{ICC}(2)$ for the items was .76 while the $\operatorname{ICC}(2)$ for the scale was .76. Currently, scholars suggest that ICC(2) values greater than .70 are acceptable indicating the workgroup mean of affective organizational commitment is reliable (Klein et al, 2000). These results suggest there is adequate agreement and reliability of affective commitment between workgroup members to aggregate individual commitment into a measure of workgroup commitment satisfaction by calculating the mean of the employees in the workgroups.

Table 1 Scale and Item ICC(1) and ICC(2) for Affective Organizational Commitment

\section{Scale/Item}

I feel a strong sense of belonging to this organization.

I am willing to work harder than I have to in order to help this company succeed.

I am proud to be working for this company.

I find that my values and this company's values are similar. I would turn down a job with more pay in order to stay with this company.

Average of Affective Organizational Commitment Items
ICC(1)

.16

.12

.18

.14

.16

.17
$\operatorname{ICC}(2)$ .77 .70 .79 .75 .77 .77 
Voluntary Turnover. A measure of workgroup voluntary turnover was constructed from information provided by the HR managers one year following the collection of HR practice data and employee commitment data. For each workgroup, the business-unit HR manager was asked: "In the past 12 months how many employees in each job category quit or left [company name] voluntarily?" This number was then divided by the average number of employees in the job category over the last 12 months (provided by the corporate office). The histogram and normal probability plot were skewed thus the variable was transformed by adding .10 and taking the natural logarithm. The transformation made the distribution closer to normal.

Human Resource Management Practices. Information about the human resource management practices was collected with surveys from both the employees and the HR managers. To avoid the mono-method bias associated with using employee perceptions of HR practices to predict employee attitudes and behaviors, only information collected from the HR managers was used in the empirical model.

There are at least three streams of thought regarding the best way to measure HR practices using organizational informants. Huselid (1995) asked informants the percentage of employees covered by the list of HR practices. Ichniowski et al (1997) and others (MacDuffie, 1995) primarily used questions that objectively assessed the presence or absence of the HR practice or policy. This method is most commonly used when information is being collected at the job level. Finally, some scholars have used questions with a Likert-type scale to assess the extent of usage or importance of the practice (Delery \& Doty, 1996).

We chose to ask respondents specific, objective questions about the use of HR practices for three reasons. First, since our informants were able to provide information at the workgroup within each organization, if an HR practice was present, it covered the entire group. Second, there is active debate in the literature regarding the extent of random and systematic error in measures of HR practices. Recent research suggests respondents may be biased by the perceived performance of their firm when providing evaluative information about HR 
practices. Asking objective information is likely to reduce these biases (Gerhart et al, 2000;

Huselid, 1995; Huselid \& Becker, 2000). Third, since the theoretic model specifically excludes questions relating to the maximization of the effectiveness of HR practices (i.e. fit, implementation, effectiveness) we needed only collect information about the practices' presence or absence.

The HR managers provided separate responses for each HR practice question for each of the five workgroups in their business-units. The questions focusing on the presence or absence of specific HR practices allowed the respondents to indicate "Yes," "No," or "I don't know." The list of questions can be found in Table 2. The presence of an HR practice was scored a one and the absence was scored a zero. One question asking about the number of hours of training per year was scored one for 15 or more hours of training per year and zero for fewer than 15 hours $^{2}$. Questions about the frequency of communication were scored as one for quarterly or more frequently and zero for annually or never. The indicator scores were combined into an additive index for each of the three HR subdimensions. "I don't know" responses were scored as not having the practice. This may seem an inappropriate use of missing data. However each business-unit employs approximately 500 employees. If the top HR manager does not know about the existence of an HR practice in such a small facility it is prudent to conclude the practice does not exist. The first author contacted the corporate HR staff and several business-unit HR managers to confirm this hypothesis. The consensus was that circling "I don't know" meant "not to my knowledge" an alternative answer for "No."

The HR practice questions listed in Table 2 were organized by their classification into skill enhancing, motivation enhancing, and empowerment enhancing practices. Practices classified as skill enhancing were those that function to improve the knowledge, skills, and abilities of the collective workgroup through pre-hire selection and post-hire training. Motivation

\footnotetext{
${ }^{2}$ Fifteen hours was used as the cutoff based on a study of employer provided training conducted by the Bureau of Labor Statistics (Frazis, Gittleman, Harrigan, \& Joyce, 1998). Both employers and employees of establishments of this size in the wholesale trade industry report employees receive 16 to 24 hours of training each year. Fewer than 15 hours is well below industry averages.
} 
enhancing HR practices were those designed to affect the motivational forces that energize, sustain, direct, and stop work behavior. These practices include performance evaluation, pay for performance, and promotion programs. Empowerment enhancing HR practices are those designed to encourage employees to effectively contribute their knowledge and abilities to workgroup and organizational success. This includes participation, dispute resolution, and communication (Appelbaum et al, 2000).

Table 2 Human Resource Management Practice Questions ${ }^{a}$

\section{Skill Enhancing HR Practices}

1. Applicants undergo structured interviews (job related questions, same questions asked of all applicants, rating scales) before being hired.

2. Applicants for this job take formal tests (paper and pencil or work sample) before being hired.

3. On average how many hours of formal training do employees in this job receive each year? ${ }^{b}$

4. The results of the performance evaluation process are used to determine the training needs for employees in this job.

5. Employees in this job have the opportunity to receive tuition reimbursement for completing college classes.

\section{Motivation Enhancing HR Practices}

6. Employees in this job regularly (at least once a year) receive a formal evaluation of their performance.

7. Pay raises for employees in this job are based on job performance.

8. Employees in this job have the opportunity to earn individual bonuses (or commissions) for productivity, performance, or other individual performance outcomes.

9. Employees in this job have the opportunity to earn group bonuses (or commissions) for productivity, performance, or other group performance outcomes.

10. Employees in this job have the opportunity to earn company-wide bonuses (or commissions) for productivity, performance, or other operating company performance outcomes.

11. Qualified employees have the opportunity to be promoted to positions of greater pay and/or responsibility within the company.

\section{Empowerment Enhancing HR Practices}

12. Employees in this job have a reasonable and fair complaint process.

13. Employees in this job are involved in formal participation processes such as quality improvement groups, problem solving groups, roundtable discussions, or suggestion systems.

14. Employees in this job communicate with people in other departments to solve problems and meet deadlines.

How often do employees in this job receive formal company communication regarding: ${ }^{\mathrm{c}}$

15. Company goals (objectives, actions, etc)?

16. Operating performance (productivity, quality, customer satisfaction, etc.)?

17. Financial Performance (profitability, stock price, etc.)?

18. Competitive performance (market share, competitor strategies, etc.)?

a With the exception of those marked, the response option for these questions was "Yes, No, I don't know."

${ }^{\mathrm{b}}$ Response option was "Hours

${ }^{c}$ Response options for these questions were: "Never, Annually, Quarterly, Monthly, Weekly, Daily." 
The classification of the practices into the three categories was conducted by the three authors with disagreements resolved through discussion. This method was identified as superior to such methods as factor analysis or cluster analysis. These statistical techniques assume HR practices are systematically developed and implemented by HR and top management executives and seek to identify these underlying trends (Delery, 1998). Johns (1993) noted a large variety of political and other pressures, not systematic planning, that affect the use of HR practices. Similarly, in a survey of 14 large organizations, Wright et al (1998) found that individual HR practices were, in most companies, working at cross purposes rather than systematically aligned. Lacking empirical evidence to assume underlying constructs, grouping the practices by their theoretical, functional outcomes and adding them together to create sub-indices seemed the most appropriate course (Delery, 1998).

To validate the measure of the three types of HR practices, the data provided by the HR managers was compared to HR practice data provided by employees. Due to restrictions imposed by the company, several questions on the HR managers' survey were excluded from the employee survey. However, with regard to the employee reports of HR practices, the average ICC(1) for the remaining of HR practice items was .17; the average ICC(2) was .76. This (a) suggests an adequate degree of agreement among employees in the distinct workgroups regarding the presence or absence of the individual HR practices and (b) provides strong evidence that the configuration of HR practices is unique for each workgroup in each business unit. The correlation between the measures of skill, motivation, and empowerment HR practices measured with employee and HR manager data was $.34, .64$, and $.48(p<.001)$ respectively ${ }^{3}$. The correlation between the employees' and HR managers' responses for a complete index of HR practices was $.63(p<.001)$. These correlations suggest the data

\footnotetext{
${ }^{3}$ We calculated a correlation between the skill, motivation, and empowerment indices using employee and HR manager data. The indices calculated using HR manager data were calculated as above less the practices missing from the employee survey. For the employee data, the percentage of employees in each work group indicating the existence of the practice was calculated for each practice. The skill, motivation, and empowerment indices were then constructed by calculating the mean of the appropriate practices for each dimension.
} 
collected from the HR managers reasonably represents the state of HR practice in the business units.

Control Variables. Five control variables were used to reduce the power of alternative explanations of workgroup voluntary turnover. Research has demonstrated unionized employees have different levels of commitment $\{$ Hammer \& Avgar 2005\} and turnover $\{$ Freeman $1980\}$ than non-union employees. There is debate in the literature as to whether the proportion of women in the workplace is associated with higher turnover \{Batt et al 2002\}. Gender was captured in the employee survey and the proportion of females was calculated for each workgroup. Tenure is consistently identified as a negative predictor of voluntary turnover\{Hom \& Griffeth 1995\}. The average tenure of the employees in each workgroup was calculated. Consistent with the March and Simon (1958) model of turnover, greater outside opportunities, in the form of low unemployment rates has an impact on organizational turnover rates $\{$ Terborg \& Lee 1984\}. Thus local unemployment rate for each business unit between the time of the survey and the later measure of turnover was included in the model. Finally, employees with higher levels of education will have greater employment opportunities. Thus the average education level of the employees in each workgroup was calculated.

Analytical Strategy. We used Shrout and Bolger's (2002) revision of Baron and Kenny's (1986) procedures for testing mediation hypotheses in an OLS regression framework.

Clustered robust regression was used to account for the clustering of the 93 workgroups in the 20 business units. This procedure estimates robust standard errors to compensate for the fact that observations within clusters may be correlated resulting in heteroskedastic error terms \{Rogers 1993; Williams 2000\}. The residuals from the six clustered regression with robust standard error models outlined in Table 4 were normally distributed.

\section{Results}

The descriptive statistics and zero order correlations can be found in Table 3 . The test of the hypotheses can be found in Table 4. 
Table 3

Descriptive Statistics And Zero Order Correlations

\begin{tabular}{|c|c|c|c|c|c|c|c|c|c|c|c|}
\hline Variables & Mean & s.d. & 1 & 2 & 3 & 4 & 5 & 6 & 7 & 8 & 9 \\
\hline 1. Unemployment Rate & 3.87 & 1.78 & & & & & & & & & \\
\hline 2. Union Status & .15 & .36 & -.13 & & & & & & & & \\
\hline 3. Proportion Female & .19 & .22 & .04 & $-.33^{* *}$ & & & & & & & \\
\hline 4. Education Level & 3.04 & .64 & .02 & $-.36^{* * *}$ & $.52^{\star \star *}$ & & & & & & \\
\hline 5. Tenure & 3.78 & .65 & $.21^{*}$ & -.07 & .09 & .07 & & & & & \\
\hline 6. Skill HR Practices & 2.81 & 1.38 & .17 & $-.29^{\star *}$ & -.03 & -.01 & .15 & & & & \\
\hline 7. Motivation HR Practices & 3.67 & 1.49 & $.21^{*}$ & $-.66^{\star \star \star}$ & $.44^{\star \star *}$ & $.50^{\star \star *}$ & .13 & $.23^{*}$ & & & \\
\hline 8. Empowerment HR Practices & 3.73 & 1.25 & $.23^{*}$ & $-.34^{* \star \star}$ & $.32^{* *}$ & $.34^{* *}$ & .06 & $.26^{*}$ & $.38^{* * *}$ & & \\
\hline 9. Collective Affective Commitment & 3.68 & .40 & .17 & $-.57^{* \star \star}$ & $.25^{*}$ & $.51^{* * *}$ & .09 & $.21^{*}$ & $.57^{\star \star *}$ & $.51^{* \star *}$ & \\
\hline 10. Log of Turnover & .17 & .16 & $-.25^{\star}$ & $.26^{*}$ & $-.36^{* * *}$ & $-.37^{\star \star \star}$ & ${ }^{*}-.26^{*}$ & $.20^{*}$ & $-.40^{* * *}$ & $-.32^{* *}$ & $-.41^{* * *}$ \\
\hline
\end{tabular}

Table 4

Results of OLS Regression Analysis

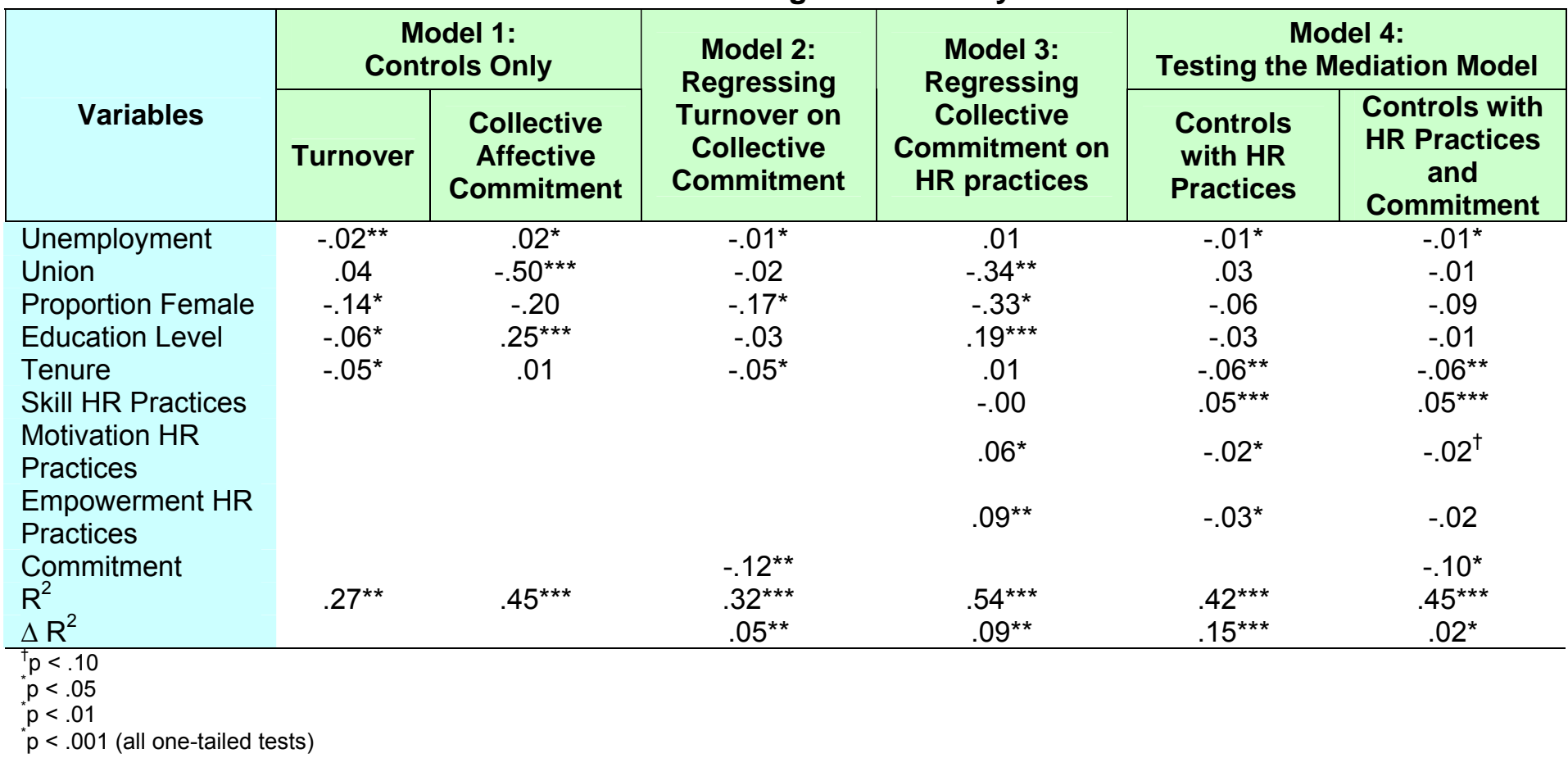


Hypothesis 1 suggests that workgroup turnover rate will be negatively related to collective affective organizational commitment. The zero-order correlation between collective commitment and turnover is $-.41(p<.001)$. Model 2 in Table 3 suggests that introducing the commitment variable into the control variable model explains an additional $5 \%$ of turnover variance $(p<.01)$. The beta coefficient is, as expected, negative, supporting Hypothesis 1 .

Hypotheses $2 \mathrm{a}, 2 \mathrm{~b}$, and $2 \mathrm{c}$ predict that skill, motivation, and empowerment enhancing practices will be positively associated with collective commitment. The correlation table suggests all three sets of practices are positively related to commitment $(p<.05$ or lower). Model 3 in Table 4 shows that entering skill, motivation, and empowerment enhancing practices into the regression equation after the set of five control variables explains an additional $9 \%$ of the variance in workgroup turnover $(p<.01)$. Contrary to the zero-order correlation, the coefficient for skill enhancing practices is not significant. The coefficients for motivation enhancing and empowerment enhancing practices are significant and, as expected, positive. These results support Hypotheses $2 \mathrm{a}$ and $2 \mathrm{~b}$ but not $2 \mathrm{c}$.

Hypotheses 3 suggests that collective affective commitment will fully mediate the relationship between motivation and empowerment enhancing practices and aggregate turnover and partially mediate the relationship between skill enhancing HR practices and aggregate turnover. Shrout and Bolger's (2002) revision of Baron and Kenny's (1986) four step process to assess mediation was used to test these hypotheses. Step one is to ensure the mediator (commitment) is associated with the dependent variable (turnover). The results for Hypothesis 1 supported this relationship. Step two involves testing for a relationship between the main variables (skill, motivation, empowerment enhancing practices) and the mediating variable (commitment). The results for Hypotheses $2 \mathrm{a}$ and $2 \mathrm{~b}$ support the association between motivation and empowerment enhancing practices. Lacking an association between skill enhancing practices and commitment there can be no mediation. Step 3 is to test for an association between the main variables and the dependent variable. Model 4 , in Table 4 shows 
that the inclusion of the three HR practice bundles explains an additional $15 \%(p<.001)$ of the turnover variance. As expected, skill enhancing practices are positively associated with turnover. The greater the use of skill enhancing HR practices to manage the human capital in a workgroup, the greater the aggregate turnover. Motivation and empowerment enhancing practices are negatively associated with turnover. The greater use of these sets of practices the lower the aggregate turnover of the workgroup. The second portion of Model 4 in Table 4 tests the final step of the Baron and Kenny (1986) process. The inclusion of the commitment variable in the model that includes the five control variables and the three HR practice variables explains an additional $2 \%$ of the variance $(p<.05)$ of turnover. The commitment coefficient is, as expected, negative. Most importantly, the coefficients for motivation and empowerment enhancing practices changed from full significance to marginal and non-significance, respectively, apparently supporting Hypotheses $3 a$ and $3 b$.

Numerous authors have criticized the Baron and Kenny (1986) procedure for assessing mediation for its lack of precision in identifying the presence of mediation and the estimation error resulting from using Sobel tests to estimate confidence intervals with small samples ( < 400 cases $)^{4}$. We chose to use the bootstrap resampling method outlined in Shrout and Bolger (2002) to formally assess the statistical significance of the mediation effects observed above. This procedure requires many fewer assumptions than the Baron and Kenny (1986) approach, provides tests of significance in samples as few as 20 , and is widely accepted across a variety of literatures \{MacKinnon et al. 2007; Shrout and Bolger 2002\}.

Using Stata 9.2 we used bootstrapping with replacement to generate 1000 samples of the entire data set accompanied by 1000 estimates of Models 3 and $4 \mathrm{~b}$ in Table 4 allowing us to calculate 1000 estimates of the indirect effect of motivation enhancing practices on turnover and empowerment enhancing practices on turnover. The mean indirect effect for motivation enhancing practices was -.004 with a $95 \%$ confidence interval of -.0043 to -.0037 . The mean

\footnotetext{
${ }^{4}$ See Shrout and Bolger (2002), especially page 425, for a list of papers critical of the Baron and Kenny (1986) approach and detailed explanation of its shortcomings.
} 
indirect effect for empowerment was -.009 with a 95\% confidence interval of -.0097 to -.00897 . As neither of these confidence intervals included zero, the mediation effects identified using the Baron and Kenny (1986) method were statistically significant. Dividing the indirect effect coefficients by the direct effect coefficients estimated in Model 4a in Table 4 suggests collective affective commitment mediates $16 \%$ of effect of motivation enhancing practices impact on aggregate turnover and mediates approximately $35 \%$ of the effect of empowerment enhancing practices on aggregate turnover. These results are more consistent with partial not full mediation providing only partial support for Hypotheses 3a and 3b.

\section{Discussion}

Aggregate voluntary turnover is the tangible evidence of a large number of decisions regarding quitting and staying across a set of individuals over time. While individual turnover decisions are of great importance to immediate supervisors, general managers pay attention and direct resources to controlling the aggregate turnover of workgroups, divisions, business units, and enterprises $\{$ Baysinger \& Mobley 1983\}. This study makes theoretical contributions useful for understanding this important phenomenon.

Empirically, the results of this study suggest a negative relationship between collective affective commitment and aggregate voluntary turnover. All else being equal, a one standard deviation increase in a workgroup's collective commitment will be associated with a $4.92 \%$ reduction in voluntary turnover. Average turnover rate in this sample was $18.5 \%$ suggesting a $26.6 \%$ relative decrease in turnover. A one standard deviation increase in skill enhancing practices will be associated with a $7.14 \%$ raw and $38.6 \%$ relative increase in voluntary turnover. A one standard deviation increase in motivation enhancing practices will be associated with a $3.02 \%$ raw and $16.3 \%$ relative decrease in voluntary turnover. Of the raw decrease in turnover, $.49 \%$ is mediated by collective commitment and $2.54 \%$ appears to be a direct effect. A one standard deviation increase in empowerment enhancing practices will be associated with 
a $3.82 \%$ raw and $20.6 \%$ relative decrease in voluntary turnover. Of the raw decrease in turnover $1.34 \%$ is mediated by collective commitment and $2.48 \%$ appears to be a direct effect. The empirical results of this study inform several debates in the aggregate turnover and strategic HR literatures. First, by disaggregating HR practices into functional bundles we were able to test for differential effects of specific bundles on affective commitment and turnover. This is by no means a new innovation. Appelbaum et al (2000), Batt (2002), Whitener (2001) all used a similar framework to categorize HR practices into similar categories. This is the first study to cluster a large set of HR practices in concordance with Dyer and Holder's (1988) original framework, propose the various mechanisms by which each bundle will impact employee attitudes and behavior, and most importantly, propose and find that different bundles impact employee outcomes differently. The findings of this study suggest that functional bundles of HR practices will explain more variance than simple additive indices. Future researchers are encouraged to use and refine the techniques found in this study.

Second, while we did not explicitly test the theoretical rationale used to support our associational hypotheses, the strong methodological and analytical techniques found in this paper should provide strong impetus for researchers wanting to move beyond the question whether collective affective commitment is associated with aggregate voluntary turnover to examining why and under what conditions these associations exist. Early work suggests feelings of engagement are transmitted from less to more engaged team members \{Bakker et al 2006\}. Emotional contagion models may be useful for demonstrating the diffusion of commitment among groups, subsequent norm formation, and impact on voluntary turnover.

Third, our results informs the about whether collective commitment fully or partially mediates the relationship between HR practices and aggregate voluntary turnover. We expected to provide much greater insight into this discussion by disaggregating our measures of HR practices into the three functional bundles. This methodological innovation helped to some degree but raised additional questions. The positive, direct association between skill enhancing 
practices and aggregate voluntary turnover and the unexpected partial mediation observed for motivation and empowerment enhancing practices clearly support the partial mediation side of the debate.

One explanation for the partial mediation effect might be found in the "unfolding model" of turnover \{Lee \& Mitchell 1994\}. Unlike the deliberative psychological process of withdraw and turnover that has dominated the individual turnover literature for the last several decades, the unfolding model posits that the turnover decision-making process following from the interpretation of a "shock" or very distinguishable event operates very differently from the decision process resulting from general lack of commitment or satisfaction. For instance, following an incident of sexual harassment, an employee may quit without first finding alternative employment. Kammeyer-Mueller et al (2005) demonstrated that the effect of critical events on turnover is unmediated by commitment. The unfolding model has exclusively focused on individual reaction to categories of shocks $\{$ Lee et al 1996\}. However, Krackhardt and Porter (1986) showed that workgroup turnover rates are affected by supra-individual shocks. One possible explanation for our findings is that sets of human resource practices might homogenize decision-makers' schema regarding the interpretation and action plans following common events thus affecting aggregate turnover behavior independent of collective commitment. Consistent with the above call for research on the diffusion of commitment sentiments, our findings also suggest fruitful work examining the diffusion of decision scripts among interacting co-workers.

Virtually all models attempting to describe the "black box" between HR systems and firm performance suggest HR practices impact employee behavior which then affects operating and financial performance $\{$ Wright \& Gardner 2003\}. As the unit of analysis for this study was the workgroup, we can only make limited contribution to this debate. Unlike past research, which has focused almost exclusively distal outcomes (operational, accounting, financial), this study is the first to examine the impact on the most proximal outcomes, employee attitudes and behavior. 
Our results suggest that collective attitudes play an important role in this larger mediating model and must be included in future theoretical and empirical refinements of this model. We expect that the partial mediation results found here will also be found at all linkage points of the hypothetical black box. Future researchers are encouraged to think carefully about the mediating links from HR practices to employee outcomes, to firm outcomes but also the direct links between HR practices and these more distal outcomes.

There are several limitations to this study that need to be considered in evaluating the results reported. First, we did not include a measure of workgroup pay level as a component of one of the functional HR bundles or as a control. Despite the lay press emphasis on the importance of pay, we feel this is only a minor omission. Hom and Griffeth's (1995) metaanalysis concluded that pay level and turnover were only correlated at -.06 at the individual level. In a meta-analysis of 7 studies that included 1645 firms and business units, the population estimate of the correlation between pay level and aggregate turnover rate was -.11 but the $90 \%$ confidence interval included zero \{Bradley 2006\}.

Secondly, an important factor that might have explained variation in employee attitudes and turnover is the attributes and behavior of the workgroup supervisor \{Fleishan \& Harris 1962\}. We would suggest that there is a fair amount of homogeneity among supervisors in the same business unit and this inter-business unit variation was subsequently controlled through our robust regression techniques. Future researchers should consider controlling for supervisor attributes.

Finally, the results of this study may not be generalizable to settings outside of service or even food service. We believe that the complex nature of food service warehousing, delivery and sales makes this study generalizable to a large portion of the U.S. economy but additional studies in other industries or multi-industry studies may be needed overcome these effects.

On the positive side, however, this study provided a more rigorous test of the issues we explored. This study used a true longitudinal design as opposed to a retrospective longitudinal 
design (asking HR managers to estimate HR practices or employees to estimate their commitment in the distant past) or a post-predictive design (measuring a metric like turnover that has taken place in the past at the same time current attitudes or HR practices are measured). Voluntary turnover as opposed to total turnover was measured. Common method bias was nearly a non-issue as collective commitment and HR practices were measured using different sources; HR practices and aggregate voluntary turnover were measured 12 months apart. We used an established set of control variables that controlled for human capital (gender, education, tenure) and contextual (unionization and local unemployment rates) factors that might have explained variation in aggregate turnover rates. Human resource practices were measured at the workgroup as opposed to the business unit level allowing much more accuracy in estimate of the practices $\{$ Gerhart et al 2000\}. Robust regression was used to account for the common variance from having data from multiple workgroups from the 20 participating business units. Appropriate procedures were used to aggregate the individual level commitment measure to a common level of analysis. Finally, we used a log transformation of the aggregate turnover variable to reduce problems with heteroskedasticity associated with a ratio dependent variable.

The results of this study suggest practical implications for managers. First, these results suggest that much of what we know from the vast literature on individual affective commitment and voluntary turnover is applicable for managing collective commitment and turnover. Managers that work to improve the collective commitment of their workgroups will be rewarded with lower voluntary turnover.

Specific to this study, we would suggest managers wanting to reduce voluntary turnover implement empowerment enhancing practices such as grievance procedures, information sharing, and input into decisions. Allowing the interaction among employees that facilitate empowerment may also work to diffuse feelings of commitment and embed employees in their work based social network further tying them to the organization \{Holtom \& Inderrieden 2006\}. 
While the data from this study suggest skill enhancing practices actually increase voluntary turnover, we see great possibilities from the practice of selecting employees by their propensity to commit to the organization. Our measure of skill enhancing practices only examined the extent of usage of general selection devices such as structured interviews and standardized tests. Barrich and Zimmerman's (2005) work suggests biodata and attitudinal measures assessed before hire predicted later voluntary turnover. Lee et al (1992) showed that propensity to commit to an organization, prior to hire, also predicted voluntary turnover. Based on the findings of this study, we would expect that the use of these practices to make ongoing selection decisions will be associated with a lower aggregate rate of voluntary turnover.

Finally, HR researchers and practitioners conclude that greater use of HR practices is better than fewer BBecker \& Huselid, 1998\}. Our findings suggest these conclusions might be simplistic. Investments in employees via HR practices will not always be captured by the firm. Cappelli and Neumark (2001) concluded the impact of an entire set of HR practices on organizational outcomes was mixed due to increased firm labor costs. Our study would suggest that increases in labor costs are not necessarily associated with all HR practices but those that make employee skills more valuable in the broader market place. Future research should examine which HR practices increase employee mobility and thus turnover. Researchers may also want to explore bundles of practices that motivate and empower employees to achieve desired outcomes while developing the set of skills that increase firm specific productivity and not employee mobility.

In conclusion, since Hulin (1968) it has been recognized that certain sets of human resource practices can be used to lower voluntary turnover. This study confirms these past findings utilizing methodological and analytical techniques rarely found together and advances our fine-grained understanding of associative relationships. It is hoped that this work will provide the impetus for additional research to move our understanding from association to causation and from understanding the mediating mechanisms within workgroups to the firm. 


\section{References}

Allen, N. J., \& Grisaffe, D. B. 2001. Employee commitment to the organization and customer reactions: Mapping the linkages. Human Resource Management Review, 11: 209-236.

Angle, H., \& Perry, J. 1981. An empirical assessment of organizational commitment and organizational effectiveness. Administrative Science Quarterly, 26: 1-14.

Appelbaum, E., Bailey, T., \& Berg, P. 2000. Manufacturing Advantage: Why high performance work systems pay off. Ithaca, NY: ILR Press.

Arthur, J. B. 1994. Effects of human resource systems on manufacturing performance and turnover. Academy of Management Journal, 37 (3): 670-687.

Barsade, S. G. 2002. The ripple effect: Emotional contagion and its influence on group behavior. Administrative Science Quarterly, 47: 644-675.

Batt, R. 2002b. Managing customer services: Human resource practices, quit rates, and sales growth. Academy of Management Journal, 45: 587-597.

Batt, R., Colvin, A. J. S., \& Keefe, J. 2002a. Employee voice, human resource practices, and quit rates: Evidence from the telecommunications industry. Industrial and Labor Relations Review, 55: 573-594.

Baysinger, B. D., \& Mobley, W. H. 1983. Employee turnover: Individual and organizational analysis. In K. M. Rowland \& G. R. Ferris (Eds.), Research in Personnel and Human Resource Management : 269-319. Greenwich, CT: JAI Press.

Becker, B., \& Gerhart, B. 1996. The impact of human resource management on organizational performance: Progress and Prospects. Academy of Management Journal, 39 (4): 779801.

Beyer, J. M., Hannah, D. R., \& Milton, L. P. 2000. Ties that bind: Culture and attachments in Organizations. In N. M. Ashkanasy, C. P. M. Wilderom \& M. F. Peterson (Eds.), Handbook of Organizational Culture and Climate : 323-338. Thousand Oaks, CA: Sage Publications, Inc.

Boorstin, J. 2005. Delivering at Domino's Pizza. Fortune, 151, 7 February: 18.

Bowen, D. E., \& Ostroff, C. 2004. Understanding HRM-firm performance linkages: The role of "strength" of the HRM system. Academy of Management Journal, 29: 203-221.

Caldwell, D. F., Chatman, J. A., \& O'Reilly, C. A. 1990. Building organizational commitment: A multifirm study. Journal of Occupational Psychology, 63: 245-261.

Cohen, A. 1993. Organizational commitment and turnover: A meta-analysis. Academy of Managment Journal, 36: 1140-1157.

Delery, J. E. 1998. Issues of fit in strategic human resource management: Implications for research. Human Resource Management Review, 8: 289-309.

Delery, J. E., \& Shaw, J. D. 2001. The strategic management of people in work organizations: Review, synthesis, and extension. Research in Personnel and Human Resource Management, 20: 165-197.

Dyer, L., \& Holder, G. W. 1988. A strategic perspective of human resource management. In L. Dyer (Ed.), Human Resource Management: Evolving Roles and Responsibilities : 1.11.46. Washington, D.C.: The Bureau of National Affairs.

Dyer, L., \& Reeves, T. 1995. HR strategies and firm performance: What do we need to know and where do we need to go? International Journal of Human Resource Management, 6: 656-670.

Eisenberger, R., Armeli, S., Rexwinkel, B., Lynch, P. D., \& Rhodes, L. 2001. Reciprocation of perceived organizational support. Journal of Applied Psychology, 86: 42-51.

Eisenberger, R., Huntington, R., Hutchiison, S., \& Sowa, D. 1986. Perceived organizational support. Journal of Applied Psychology, 71: 500-507.

Freeman, R. B. 1980. The exit-voice tradeoff in the labor market: Unionism, job tenure, quits, and separations. The Quarterly Journal of Economics, 94: 643-673. 
George, J. M., \& Bettenhausen, K. 1990. Understanding prosocial behavior, sales performance, and turnover: A group-level analysis in a service context. Journal of Applied Psychology, 75: 698-709.

Glebbeek, A. C., \& Bax, E. H. 2004. Is high employee turnover really harmful? An empirical test using company records. Academy of Management Journal, 47: 277-286.

Guthrie, J. P. 2001. High involvement work practices, turnover, and productivity: Evidence from New Zealand. Academy of Management Journal, 44: 180-190.

Hom, P. W., \& Griffeth, R. W. 1995. Employee Turnover. Cincinnati, OH: South-Western College Publishing.

Huselid, M. A. 1995. The impact of human resource management practices on turnover, productivity, and corporate financial performance. Academy of Management Journal, 38: 635-672.

Kanter, R. M. 1968. Commitment and social organization: A study of commitment mechanisms in utopian communities. American Sociological Review, 33: 499-517.

Klein, K. J., Dansereau, F., \& Hall, R. J. 1994. Levels issues in theory development, data collection, and analysis. Academy of Management Review, 19: 195-229.

Koslowski, S. W. J., \& Klein, K. 2000. A multilevel approach to theory and research on organizations: Contextual, temporal, and emergent processes. In K. J. Klein \& S. W. J. Kozlowski (Eds.), Multilevel Theory, Research, and Methods in Organizations : 3-90. San Francisco: Jossey- Bass.

Lee, T. W., \& Mitchell, T. R. 1994. An alternative approach: The unfolding model of voluntary employee turnover. Academy of Management Review, 19: 51-89.

Lee, T. W., Mitchell, T. R., Sablynsky, C., Burton, J. P., \& Holtom, B. C. 2004. The effects of job embeddedness on organizational citizenship, job performance, volitional absences, and voluntary turnover. Academy of Management Journal, 47: 711-722.

Levinson, H. 1965. Reciprocation: The relationship between man and organization. Administrative Science Quarterly, 9: 370-390.

Lincoln, J. R., \& Kalleberg, A. L. 1996. Commitment, quite, and work organization in Japanese and U.S. Plants. Industrial and Labor Relations Review, 50: 39-59.

Lindsley, D. H., Brass, D. J., \& Thomas, J. B. 1995. Efficacy-performance spirals: A multilevel perspective. Academy of Management Review, 20: 545-678.

Long, R. L. 1980. Job attitudes and organizational performance under employee ownership. Academy of Management Journal, 23: 726-737.

MacKinnon, D. P., \& Dwyer, J. H. (1993). Estimating mediated effects in prevention studies.

Evaluation Review, 17, 144-158.

MacKinnon, D. P., Warsi, G., \& Dwyer, J. H. (1995). A simulation study of mediated effect

measures. Multivariate Behavioral Research, 30(1), 41-62.

Maertz, C. P., \& Campion, M. A. 2004. Profiles in quitting: Integrating process and content turnover theory. Academy of Management Journal, 47: 566-582.

March, J., \& Simon, H. 1958. Organizations. New York: Willey.

Meyer, J. P., \& Allen, N. J. 1997. Commitment in the Workplace: Theory, Research, and Application. Thousand Oaks, CA: Sage Publications.

Meyer, J. P., \& Herscovitch, L. 2001. Commitment in the workplace: Toward a general model. Human Resource Management Review, 11: 299-326.

Meyer, J. P., \& Smith, C. A. 2000. HRM practices and organizational commitment: Test of a mediation model. Canadian Journal of Administrative Sciences, 17: 319-331.

Meyer, J. P., Stanley, D. J., Herscovitch, L., \& Topolnytsky, L. 2002. Affective, continuance, and normative commitment to the organization: A meta-analysis of antecedents, correlates, and consequences. Journal of Vocational Behavior, 61: 20-52.

Mobley, W. H. 1982. Employee turnover: Causes consequences, and control. Reading, MA: Addison-Wesley. 
Morgeson, F. P., \& Hofmann, D. A. 1999. The structure and function of collective constructs: Implications for multilevel research and theory development. Academy of Management Review, 24: 249-265.

Morrison, E. W. 2002. Newcomers' relationships: The role of social network ties during socialization. Academy of Management Journal, 45: 1149-1160.

Mowday, R. T., Porter, L. W., \& Steers, R. M. 1982. Employee-Organization Linkages: The Psychology of Commitment, Absenteeism, and Turnover. New York: Academic Press.

Osterman, P. 1995. Work/Family programs and the employment relationship. Administrative Science Quarterly, 40: 681-700.

Ostroff, C. 1992. The relationship between satisfaction, attitudes, and performance: An organizational-level analysis. Journal of Applied Psychology, 78: 693-974.

Pascale, R. 1985. The paradox of 'corporate culture': Reconciling ourselves to socialization. California Management Review, 27 (2): 26-40.

Rhoades, L., Eisenberger, R., \& Armeli, S. 2001. Affective commitment to the organization: The contribution of perceived organizational support. Journal of Applied Psychology, 86: 825836.

Rogers, W. H. 1993. Regression standard errors in clustered samples. Stata Technical Bulletin, 13: 19-23..

Rousseau, D. M. 1985. Issues of level in organizational research: Multi-level and cross-level perspectives. In B. M. Staw \& L. L. Cummings (Eds.), Research in Organizational Behavior : 1-37. Greenwich, CT: JAI Press.

Ryan, A. M., Schmit, M. J., \& Johnson, R. 1996. Attitudes and effectiveness: Examining relations at an organizational level. Personnel Psychology, 49: 853-882.

Shaw, J. D., Delery, J. E., Jenkins, G. D., \& Gupta, N. 1998. An organization-level analysis of voluntary and involuntary turnover. Academy of Management Journal, 41: 511-525.

Shaw, J. D., Duffy, M. K., Johnson, J. L., \& Lockhart, D. E. 2005. Turnover, social capital losses, and performance. Academy of Management Journal, 48: 594-606.

Simons, T., \& Roberson, Q. 2003. Why managers should care about fairness: The effects of aggregate justice perceptions on organizational outcomes. Journal of Applied Psychology, 88: 432-443.

Stevens, M. 1994. A theoretical model of on-the-job training with imperfect competition. Oxford Economic Papers, 46: 537-562.

Tannenbaum, S. I., Mathieu, J. E., Salas, E., \& Bowers, J. A. 1991. Meeting training expectations: The influence of training fulfillment on the development of commitment, self -efficacy, and motivation. Journal of Applied Psychology, 76: 759-769.

Terborg, J. R., \& Lee, T. W. 1984. A predictive study of organizational turnover rates. Academy of Management Journal, 27: 793-810.

Trevor, C. O. 2001. Interactions among actual ease-of-movement determinants and job satisfaction in the prediction of voluntary turnover. Academy of Management Journal, 44: 621-638.

Way, S. A. 2002. High performance work systems and intermediate indicators of firm performance within the US small business sector. Journal of Management, 28: 765-785.

Williams, R. L. 2003. A note on robust variance estimation for cluster-correlated data. Biometrics, 56: 645-646.

Wilson, N., \& Peel, M. J. 1991. The impact on absenteeism and quits of profit-sharing and other forms of employee participation. Industrial and Labor Relations Review, 44: 454-468. 